\title{
Aspectos socioeconómicos de la agricultura de riego en la Cuenca Lerma-Chapala
}

\section{Socioeconomic aspects of irrigated agriculture in the Lerma-Chapala basin}

\author{
Sergio Vargas-VelázQuez*
}

\begin{abstract}
Between 1990 and 2003, the Lerma-Chapala basin endured several years of extraordinary drought that reduced the Lake Chapala to $14 \%$ of its total volume, threatening drinking water supplies to Guadalajara and creating a huge strain on their distribution between uses and the different regions of the basin. The solution drawn from the governmental level is to transfer water from agriculture to urban-industrial use. One way to achieve this is to generate water savings through irrigation technology; another one is the exchange of volumes or water rights. There have been considerable efforts to change the irrigation technology, without having achieved yet the desired impact at the basin level. Here, we analyse the socioeconomic status of various irrigation systems supplied mainly from surface water and which have been tackled by water policy. Based on this, we strengthen the need for specific water negotiations that recognise the socioeconomic diversity and the different usage strategies of this resource.
\end{abstract}

Keywords: water, Lerma-Chapala basin, water technology, production strategies.

\section{Resumen}

Entre 1990 y 2003, la cuenca Lerma-Chapala sobrellevó varios años de sequía severa que redujeron el lago de Chapala a $14 \%$ de su volumen total, lo que puso en riesgo el abasto de agua potable para Guadalajara y generó una gran tensión por su distribución entre usos y regiones de la cuenca. La solución trazada por el gobierno consiste en transferir agua del uso agrícola al urbano-industrial; una vía para lograrlo es generar ahorros de agua mediante la tecnificación del riego, otra es el intercambio de volúmenes o derechos de agua. Se han hecho considerables esfuerzos por cambiar la tecnología de riego, sin que esto tenga todavía las consecuencias buscadas a nivel de cuenca. Aquí se analiza la situación socioeconómica de varios sistemas de riego que se abastecen sobre todo del agua superficial, en los cuales ha tratado de actuar la política del agua. Con base en esto se afirma la necesidad de establecer negociaciones específicas por el agua que reconozcan la diversidad socioeconómica y de estrategias de uso de este recurso.

Palabras clave: agua, cuenca Lerma-Chapala, tecnología del agua, estrategias productivas.

* Instituto Mexicano de Tecnología del Agua, México. Correo-e: kuirunhari@yahoo.com.mx. 


\section{Introducción}

El agua es un recurso fundamental para el desarrollo socioeconómico, así como un activo ambiental esencial para conservar los ecosistemas y la biodiversidad. Sin embargo, el incremento del uso humano de este activo ambiental ha llevado a que se extraiga más agua del ciclo hidrológico de la que este proceso natural es capaz de proveer anualmente en varias cuencas del país. Además de alterar su distribución natural, la calidad del líquido se ha visto alterada por numerosas descargas humanas, tanto urbano-industriales como agrícolas, que reducen aún más el volumen utilizable. Esto ha llevado al cierre de cuencas hidrológicas -situación en la que ya no hay más agua que repartir para necesidades humanas adicionales-, lo cual tiene severas consecuencias tanto en el medio ambiente como en los distintos grupos humanos que hacen uso de este recurso.

En la agricultura de riego -la más productiva en la creación de alimentos- es donde se están centrando las miradas y cuestionamientos, ya que se le atribuye el mayor desperdicio de agua y el menor valor económico por metro cúbico consumido. En México han asumido esta visión distintos grupos de interés y entes gubernamentales, quienes proponen políticas hídricas para redistribuir el agua del sector hidroagrícola al urbanoindustrial, además de otras medidas de gestión de la demanda. Sin embargo, establecer un proceso equitativo de redistribución del agua es algo harto complejo que requiere reconocer el valor del riego, tanto para la producción de alimentos, como para el empleo y las redes económicas tejidas en su entorno social.

Aquí se presenta la situación de la agricultura de riego de la cuenca Lerma-Chapala, ya cerrada hidrológicamente al igual que el valle de México, la cuenca del río Bravo o la del río Balsas. En esta cuenca se dio un intenso proceso de negociación entre 1999 y 2004, el riego y el volumen de agua que se utiliza es el punto central para definir un nuevo acuerdo de distribución del agua superficial, cuyo objetivo explícito es salvar al lago de Chapala de la desecación, pero que implica una redistribución del agua de toda la cuenca. Este trabajo muestra algunos resultados del proceso de evaluación de la irrigación en la cuenca, realizados como parte del proceso de construcción de alternativas de distribución del agua analizadas en el Consejo de Cuenca Lerma-Chapala.

\section{El cierre de cuenca}

En las últimas décadas son cada vez más las regiones hidrológicas en el mundo en que la demanda de agua para necesidades humanas supera el agua que el ciclo hidrológico es capaz de renovar anualmente. De esta 
manera se dan situaciones de sobreexplotación de los recursos hídricos con considerables afectaciones al medio ambiente. Este proceso se ha conceptualizado como el cierre de cuenca (river basin closure), en tanto deja de existir disponibilidad de agua para nuevas o mayores demandas del recurso (Keller et al., 1998), e incluso se reducen o desaparecen los caudales que requieren los ecosistemas para su existencia. Esto también tiene importantes repercusiones sociales, políticas y económicas, ya que la gestión del agua deja de ser la gestión de su escasez, para convertirse en la gestión del déficit permanente de agua. Las razones que explican esto son multifactoriales, pero las fuerzas conductoras de este proceso son fundamentalmente resultado de las actividades humanas sobre el ambiente, el crecimiento demográfico y las actividades económicas, con un importante componente sociopolítico (Mollinga, 2008).

El proceso de cierre de las cuencas ocurre particularmente en regiones donde la aridez impulsó a que se construyeran grandes infraestructuras para riego, ya que ahí fue donde históricamente se implementaron en mayor medida acciones para regular y aprovechar el agua que provee el ciclo hidrológico de manera estacional. Las respuestas al cierre de una cuenca pueden ser varias, pero la solución todavía dominante -surgida del modelo de gestión centralizado del agua establecido desde la década de 1920, y todavía parcialmente vigente (Wester 2008) - enfatiza seguir garantizando la oferta de agua para el crecimiento económico con base en el gasto público, y sin mayores consideraciones sobre sus efectos sociales y ambientales. Así, se ha respondido al cierre de cuencas por medio de grandes trasvases, que implican mayores intervenciones en el ciclo hidrológico, de los cuales en el mundo hay bastantes ejemplos. En México ya tenemos numerosos casos de cuencas en etapa de cierre: las de los ríos Conchos y Balsas, el valle de México, y la cuenca Lerma-Chapala.

El cierre de una cuenca no se debe entender únicamente como un problema técnico, de eficiencia o costo-beneficio, sino fundamentalmente como un fenómeno social, y en particular, como fenómeno sociopolítico, definido mediante la relación Estado-sociedad en la que se establecen las reglas que determinan un régimen de uso del agua; entendiendo por régimen el conjunto de normas realmente vigentes que articulan y conducen al aparato estatal y sus relaciones con los distintos grupos sociales, que pueden coincidir o ser antagónicas con las normas jurídicas formalmente sancionadas en el marco institucional (O'Donnell y Schmitter, 1998). Este aspecto político del manejo del agua $-\mathrm{y}$ de todas las políticas públicas ambientales- es un elemento central que explica la pobre gobernanza del agua en muchas partes del mundo (Mollinga, 2008), incluido México (Wester, 2008). 
El cierre de una cuenca y los conflictos por el agua son procesos construidos socialmente, en los cuales las respuestas a las limitantes están dadas por los regímenes sociopolíticos, inclusive las soluciones técnicas generalmente pasan por algún filtro de carácter político, ya que ante la existencia de soluciones técnicas alternativas, los distintos grupos sociales sólo se manifiestan por aquéllas que responden a sus necesidades y perspectivas, difícilmente aceptables por todas las partes interesadas (Michelson y Van Vliet, 2002). Así, la solución a la crisis del agua no está determinada por la solución técnica a la escasez o déficit de agua, sino en la racionalidad de las instituciones que tienen que ver con el manejo del recurso, como afirma la Visión Mundial del Agua, la cual ubica la crisis del agua como una crisis de gobernanza (Cosgrove y Rijsberman, 2000). Sin embargo, se requiere entender cada estructura agraria y sus formas de acceso al agua para explicar las formas políticas y el conflicto por el agua.

La crisis del agua es una situación compleja, al mismo tiempo global y específica de cada región hidrológica, en la que se presentan enormes desafíos debido al grado de transposición de los límites de sustentabilidad en el uso del agua en muchas regiones del planeta. En el ámbito internacional han surgido diversas iniciativas para elaborar políticas públicas para manejar las cuencas hidrológicas deficitarias, las cuales han tendido a globalizarse. En la última década se ha extendido el paradigma de la gestión integrada del agua por cuenca hidrológica (GIRH), de la cual México asumió varios de sus principios en la década de 1990, y se le consideró explícitamente en la reforma a la Ley de Aguas Nacionales de 2004 (Vargas y Mollard, 2005a, b). Este nuevo enfoque de gestión critica al anterior, y se autodefine como un modelo de gestión de la demanda, en tanto enfatiza los mecanismos de regulación del uso del agua desde la política pública, así como la necesidad de transformar los arreglos institucionales hacia un manejo descentralizado y con participación social a nivel de cuenca hidrológica, en el que puedan aplicarse algunos principios de mercado en la redistribución del agua, lo cual ha sido ampliamente difundido y cuestionado a la vez (Iv Foro Mundial del Agua, 2006a, b).

En múltiples diagnósticos, e incluso en el Programa Hídrico Nacional de nuestro país, la solución para enfrentar el actual déficit en cuencas cerradas consiste en redistribuir el agua, pasando volúmenes o derechos de agua de quienes poseen o utilizan mayor cantidad -pero que le dan menor valor económico agregado-, hacia aquellos usos más eficientes, productivos o imprescindibles del agua. Esto puede ser por medio de soluciones convencionales de intervenir más en el ciclo hidrológico (más infraestructura y trasvases), o mediante diversos mecanismos concebidos en el contexto de la GIRH, como los mercados o bancos de agua, estímulos fiscales o financieros, nuevos marcos jurídicos, entre otros. 
En esta solución es la agricultura de riego la que debe ceder agua para los usuarios urbano-industriales, en tanto se estima que la agricultura utiliza entre 80 y $90 \%$ de toda el agua dulce disponible en los países en desarrollo, como es el caso de México, ya que es mucho menos lo que aporta de valor económico agregado en su uso (pesos por hectárea). La percepción convencional al respecto es, entonces, que son los agricultores quienes desperdician el agua, sin entender ni explicar las razones de este uso extensivo del agua, promovido durante décadas por las mismas agencias gubernamentales que hoy lo cuestionan. En el Programa Hídrico Nacional 2001-2006 se enunciaba que ya que es la agricultura la mayor consumidora del líquido, pero también la actividad que menor valor económico agrega, se deben implementar acciones para reducir su consumo hasta en un $6 \%$, transfiriendo este volumen ahorrado a otros usos, lo que permitiría abastecer el incremento de la demanda por el crecimiento de los usuarios urbano industriales. Este proceso ya comenzó y no es políticamente neutro, ya que tiene grandes repercusiones en la economía agrícola, el arreglo institucional del agua y el ámbito rural.

La agricultura de riego de la cuenca Lerma-Chapala ya se encuentra en esta situación. Como se analiza en el apartado 2, la cuenca está en situación de déficit desde hace varios lustros, lo que afecta cuerpos de agua como el lago de Chapala, y ha generado el enfrentamiento entre distintos usuarios a lo largo de la cuenca, lo cual analiza con profundidad Wester (2008); asimismo, varios momentos del proceso de negociación y conflicto entre las partes se tratan en Güitrón (2005), Mollard y Vargas (2002a, b, 2004), Vargas y Mollard (2005a, b) y Wester et al. (2008). En los siguientes apartados se exploran las condiciones generales de la agricultura de riego, con base en la información utilizada para la negociación del nuevo acuerdo de distribución del agua superficial de la cuenca, firmado en 2004 (Vargas et al., 2003); finalmente en las conclusiones se afirma que el cambio tecnológico en la agricultura de riego debe implicar el reconocimiento de la diversidad socioeconómica, un modelo de representación diferente al actualmente establecido en el Consejo de Cuenca Lerma-Chapala. Sin embargo, aun cuando se diseñara una política pública que considere las compensaciones necesarias para lograr la transferencia de uso del agua de la cuenca, no se lograría sin la resistencia de la amplia diversidad social y organizativa de los agricultores de riego de la cuenca Lerma-Chapala.

\section{La cuenca Lerma-Chapala}

La cuenca Lerma-Chapala se ubica en el centro occidente de México. Abarca 54,300 km² y cruza cinco estados (Querétaro, Guanajuato, Mi- 
choacán, Jalisco y México) con una superficie que representa 3\% del territorio nacional. En ella vive uno de cada 10 mexicanos: la cuenca abastece a alrededor de 16 millones de personas: 11 millones en la misma cuenca y dos millones para cada una de las ciudades de Guadalajara y México, servidas a través de sendos trasvases. El proceso de urbanización continúa y está presionando para que su entorno rural ceda agua para sus necesidades crecientes; En el año 2000, 50\% de los habitantes de la cuenca se concentraba en 27 ciudades de más de 50 mil habitantes. El aprovechamiento de los recursos hídricos ha sido soporte del desarrollo socioeconómico de esta región; la producción industrial y agrícola per cápita, por ejemplo, es superior a la media nacional. Con más de 6,400 industrias de diversos giros, en la cuenca se genera poco más de la tercera parte de la producción industrial nacional de transformación, y asimismo $20 \%$ del comercio nacional. El agua por habitante ya se encuentra por debajo de los 1,000 $\mathrm{m}^{3} / \mathrm{hab} / \mathrm{año}$, lo que significa que es una cuenca en estrés hídrico. En el estudio previo al Acuerdo de Distribución del Agua Superficial firmado en 2004, se identificaba una disponibilidad de agua superficial de $-677.6 \mathrm{hm}^{3}$ y en agua subterránea de $-875 \mathrm{hm}^{3}$. Asimismo, el hecho de que en ella se ubiquen una de cada ocho hectáreas bajo riego y una de cada ocho hectáreas dedicadas a la agricultura de temporal con que cuenta el país, indican el papel primordial que tiene ahí el sector agrícola (Güitrón, 2005). La razón por la cual se manifiesta el conflicto social por el agua superficial, pero no así en el caso del agua subterránea, se explica tanto por la manera en que operan las formas de sociales de uso de cada uno de los tipos de agua, como por el proceso sociopolítico y organizativo por el agua asociado al deterioro y cierre de la cuenca.

La agricultura consume alrededor de $80 \%$ del volumen anual utilizado en esta cuenca. Es por esto que cualquier solución al problema de la escasez construida a lo largo de décadas de expansión de la demanda de agua, tiene que transformar el uso que hacen de ella los agricultores. De ahí la tensión entre agricultores, funcionarios y ambientalistas en la cuenca Lerma-Chapala. Sin embargo, no se ha considerado en su debida importancia la dimensión del cambio tecnológico en la agricultura de riego, las condiciones de uso del agua en términos macroeconómicos y la racionalidad que le impone la economía. Sólo así se podrán comprender un poco más las grandes diferencias socioeconómicas que existen en las casi 800 mil hectáreas de riego (cuadro 1), donde coexisten sistemas productivos con base en la organización social y tecnologías de varios siglos atrás -como los sistemas con cajas de agua y entarquinado-, junto con los sistemas modernos, reorganizados con productos de la etapa desarrollista de nuestro país desde mediados del siglo xx. 


\section{Cuadro 1}

Superficie de riego en la cuenca Lerma Chapala, por tipo de sistema y subcuenca

\begin{tabular}{lrrrrrr}
\hline Subcuenca & $\begin{array}{c}\text { Distritos } \\
\text { de riego } \\
\text { (ha) }\end{array}$ & $\begin{array}{c}\text { Unidades } \\
\text { de riego } \\
\text { (ha) }\end{array}$ & $\begin{array}{c}\text { Superficie } \\
\text { total }\end{array}$ & $\begin{array}{c}\text { Agua } \\
\text { subterránea } \\
\left(\mathrm{hm}^{3} / \mathrm{año}\right)\end{array}$ & $\begin{array}{c}\text { Agua } \\
\text { superficial } \\
\left(\mathrm{hm}^{3} / \mathrm{año}\right)\end{array}$ & $\begin{array}{c}\text { Volumen } \\
\text { total }\end{array}$ \\
\hline Alto Lerma & 48,286 & 117,948 & 166,234 & 409 & 749 & 1,158 \\
Medio Lerma & 166,319 & 313,788 & 480,107 & 2,275 & 2,006 & 4,281 \\
Bajo Lerma & 68,453 & 78,414 & 146,867 & 500 & 657 & 1,157 \\
& 283,058 & 510,150 & 793,208 & 3,184 & 3,412 & 6,596 \\
\hline
\end{tabular}

Fuente: CNA-Montgomery Watson (1999).

Durante la última década, los conflictos por el agua se han generalizado en la cuenca Lerma-Chapala, lo cual se explica parcialmente por la aparición de un periodo anormalmente seco que ha reducido la disponibilidad de agua, y ha llevado a restringir el acceso en varios usos. Otra razón muy importante es el rápido crecimiento de la demanda para todos los usos, sin las debidas consideraciones ambientales. La situación de déficit reanimó las posiciones contrapuestas tanto en el ámbito gubernamental como entre los propios usuarios del agua, respecto a cómo asumir de manera equitativa las consecuencias de la escasez de agua superficial, las cuales se han manifestado con distintas intensidades y modalidades en los últimos 50 ańos mediante numerosos conflictos por el agua (Wester, 2008). La controversia principal opone a agricultores de aguas arriba, localizados mayoritariamente en el estado de Guanajuato -en la cuenca media-, y a los defensores del lago de Chapala, río abajo, en el estado de Jalisco (Caire 2005; Mollard y Vargas 2004); los agricultores de subsistencia de la cuenca alta han permanecido al margen de este conflicto, inmersos en su propia problemática (Vargas, 2007). La representación de los agricultores en las negociaciones por el agua ha estado capturada por una red de agricultores comerciales y grandes agroindustriales en el esquema de participación dirigida por la autoridad federal en el Consejo de Cuenca Lerma-Chapala.

Entre 1990 y 2003 el lago de Chapala alcanzó sólo 14\% de su capacidad de almacenamiento debido a la sequía, lo cual llevó a la movilización para defender este emblemático cuerpo de agua de los habitantes de Guadalajara. Ahí se encuentran organizaciones de la sociedad civil preocupadas por los problemas ambientales, las cuales se han movilizado desde la década de 1950 para proteger el lago de Chapala, cuestionando u oponiéndose a más infraestructura y extracciones que lo afecten. Por otro lado, las autoridades encargadas de este tema en Jalisco -tanto en la Comisión Estatal del Agua como en el sistema intermunicipal de la Zona Metropolitana de Guadalajara- se han preocupado por la conservación 
del lago de Chapala, porque mediante sus trasvases se cubre $70 \%$ de las necesidades de la segunda área metropolitana más importante del país, donde el acceso al agua es más barata, ya que la subterránea o proyectos alternativos -como en el caso de abastecimiento de la cuenca del río Verde (presas de Arcediano y Zapotillo) - resultan más costosos y conflictivos. Si bien los ecologistas y el gobierno de Jalisco coinciden en sostener el nivel del lago lo más alto posible, en otros casos se han enfrentado entre ellos y con la comisión estatal del agua.

Con la reducción del nivel del lago, se dieron algunas respuestas más impuestas que negociadas, como los sucesivos trasvases de las grandes presas de la cuenca media entre 1999 y 2003, con el fin de garantizar el abasto en Guadalajara. Esta solución convencional tuvo que acompañarse de negociaciones entre los estados e interesados en el seno del Consejo de Cuenca Lerma-Chapala, para culminar con un nuevo acuerdo de distribución del agua superficial en 2004; conflicto ya analizado en otros trabajos (Wester 2008; Wester et al., 2008).

Para responder a la crisis, la autoridad federal representada por la Comisión Nacional del Agua (Conagua) ha buscado distintos mecanismos para que se transfieran volúmenes del uso agrícola al uso urbano-industrial, y de manera suplementaria al lago de Chapala. Se han planteado mecanismos de mercado, los cuales se han rechazado por diversas razones, que van desde la debilidad del arreglo institucional y la dificultad propia de medir y parcelar el agua en una cuenca tan grande, hasta las dificultades de implementación pues se requiere un ordenamiento de derechos, ya que se afirma existe un importante nivel de sobreconcesionamiento -hay más agua concesionada en papel de la que se renueva anualmente mediante el ciclo hidrológico-. También se ha planteado la conformación de un banco del agua, figura que se estableció desde la reforma a la Ley de Aguas Nacionales de 2004, y que a pesar de varios intentos, tampoco se ha logrado llevar a cabo apropiadamente (Bravo, 2007).

Otra solución que han considerado las autoridades federales es negociar con los agricultores, para que cedan volúmenes a cambio de tecnificar sus sistemas. Así, el ahorro de agua generado con mejores tecnologías se utilizaría para sostener el lago de Chapala o cubrir la cada vez mayor demanda urbano-industrial. Esta solución ha tenido resultados limitados. En primer lugar porque los agricultores perciben que es muy riesgoso ceder agua a cambio de tecnología que los deja, desde su punto de vista, en la misma situación. La perspectiva de los agricultores es que si ahorran agua, ésta debería servir para sembrar más; y si ceden agua a otro uso o usuario, esto debe tener algún tipo de compensación; pero si la ceden mediante algún programa de tecnificación y ésta no les incrementa o 
garantiza mayor productividad, ingresos o superficie en producción o ciclos sembrados, opinan que aceptarla no les traería ninguna ventaja.

Las diversas ocasiones en que la Conagua ha presentado este tipo de propuestas de tecnificación a los agricultores de riego con agua superficial, por medio de la representación agrícola en el Consejo de Cuenca LermaChapala, el Comité Estatal Hidráulico de Guanajuato (muy vinculado a los intereses de los agricultores) o directamente con las asociaciones de usuarios, los agricultores las han rechazado, y sólo en pocos sistemas se ha llegado a implementar. Algunos ejemplos de estas negociaciones de intercambio de agua por tecnificación se pueden ver en Crinquant (2004) y Vargas et al. (2005).

Aun cuando se firmó el nuevo acuerdo de distribución de agua superficial en diciembre de 2004, y como resultado de que por un periodo de lluvias extraordinarias se recuperó el lago de Chapala, el deterioro de la cuenca es un problema innegable. Es muy probable que el conflicto reaparezca y se impulsen otra vez nuevas medidas para transferir agua de los usuarios agrícolas a los urbano-industriales, en ausencia de organizaciones que defiendan los ecosistemas de toda la cuenca. La asimetría de poder y condiciones sociales también auguran un conflicto en condiciones de desigualdad de fuerzas, pero se tiene la expectativa de que las formas de participación social en los consejos, comisiones y comités de cuenca y acuífero, creados desde 1992 con los principios de la GIRH, evolucionen de manera que permitan una solución negociada. También se requiere impulsar soluciones tecnológicas socialmente apropiadas, que respondan a las estrategias de supervivencia de los agricultores en un ambiente económico bastante enrarecido, en el que un sector de agricultores está en el umbral de la pobreza, a la expectativa de cualquier otra alternativa de vida.

\section{Características de los agricultores de riego}

Aquí se describen las características socioeconómicas de los agricultores de riego a partir de los resultados generales de la encuesta aplicada por el Instituto Mexicano de Tecnología del Agua, para caracterizar la posición de los agricultores respecto a los escenarios de distribución del agua superficial, para la firma del acuerdo de 2004 (Vargas et al., 2003). Otra parte de los resultados de dicha encuesta acerca de la disposición a ceder agua y a movilizarse por el recurso se exponen en Vargas (2008). En esta encuesta se seleccionaron sistemas susceptibles de aportar un volumen en los trasvases al lago de Chapala, por lo que no se consideraron áreas regadas con agua subterránea, o aquellos sistemas de agua superficial que por su ubicación, tamańo o disponibilidad no son capaces de aportar un volumen 
significativo, con el fin de considerar o incorporar alguno de los parámetros al respecto en el modelo de distribución del agua superficial firmado en diciembre de 2004, después de poco más de tres años de negociación.

En esta encuesta se preguntó a los agricultores su percepción sobre la problemática de toda la cuenca y su disposición a apoyar las acciones gubernamentales o, alternativamente, a movilizarse por la defensa del agua. Esto se combinó con entrevistas que resaltan las diferencias entre la base social de los agricultores y la posición que sostienen sus representantes en el Consejo de Cuenca. Se seleccionaron las zonas de riego más importantes del Medio y Bajo Lerma, se excluyó el Alto Lerma (distrito 033 y unidades) pues sus sistemas poco aportan en la redistribución del agua superficial, ya que su frecuencia de riego en el distrito 033 es de 1.2, es decir, sólo alcanza para un riego y una fracción adicional al año, además de que estuvieron ausentes en la negociación, aunque dicho acuerdo en los hechos sí los puede afectar si se presenta un nuevo periodo de sequía extraordinaria. Se seleccionaron los módulos tratando de representar los que tienen bombeo directo o sistemas mixtos, con aquéllos que sólo acceden a agua de presa. Al interior de cada sistema se seleccionaron jefes de unidades de producción, dividiendo la muestra de acuerdo con su ubicación al principio del canal o al final del mismo (mapa I).

\section{Mapa I \\ Sistemas de riego encustados}

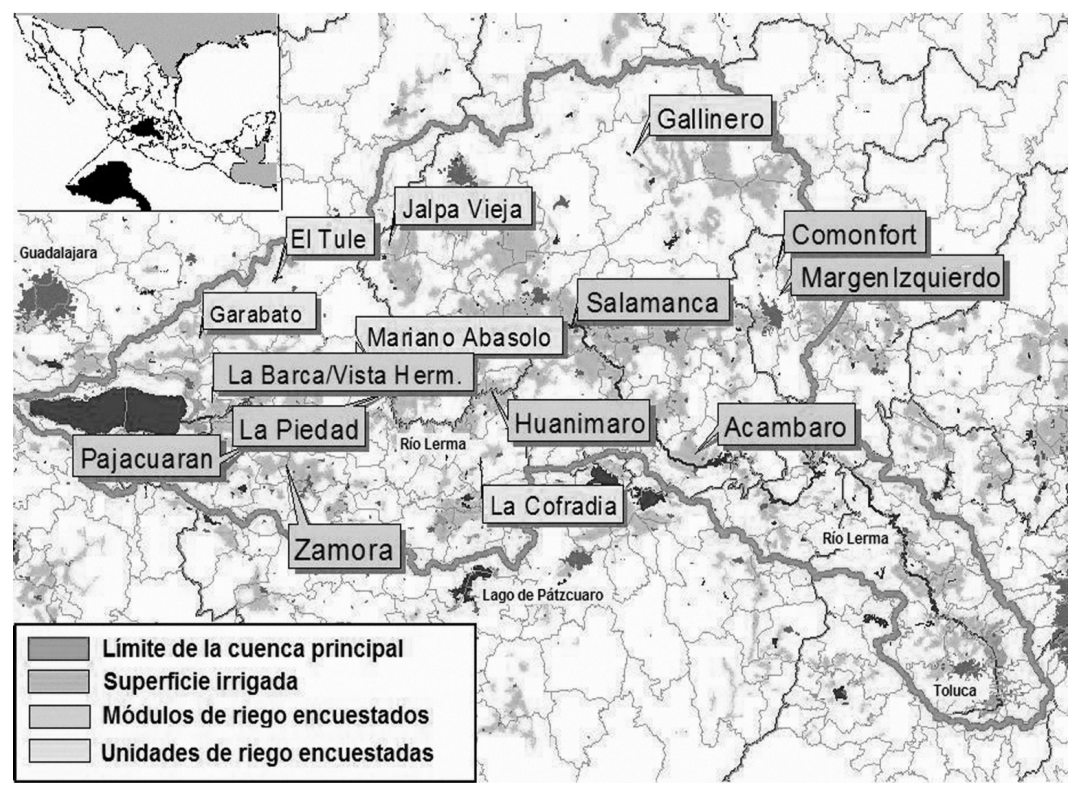

Fuente: Vargas et al. (2003). 
Aquí se analizan los resultados de la encuesta clasificando las unidades de producción de acuerdo con la superficie que concentran; es una manera simple pero permite ver ciertas tendencias generales, ya que hay una asociación significativa entre superficie con capitalización, tecnologías y rasgos sociodemográficos. Las características sociodemográficas de los agricultores de riego de la cuenca Lerma-Chapala corresponden a sistemas donde el jefe de la unidad de producción aún no ha envejecido demasiado (cuadro 2), aunque es común encontrar productores activos mayores de 70 ańos, los cuales representan alrededor de $16.7 \%$, en tanto que el mayor porcentaje y el promedio de los agricultores se encuentra en el rango de los 50 a 60 años. Una hipótesis importante en este caso es que el envejecimiento del jefe de la unidad de producción tiene que ver con varios factores. El primero es la pérdida de la importancia de la actividad agropecuaria para los ingresos familiares, y el aumento de la pluriactividad. El segundo se asocia con la distribución del trabajo en los hogares, donde por ser una actividad tradicional, con baja rentabilidad económica, el familiar de mayor edad y menor escolaridad o formación para otras actividades económicas, se queda como responsable de la agricultura. En cambio, los miembros jóvenes, con mayor escolaridad y posibilidades de movilidad laboral, abandonan el hogar, pero continúan sosteniendo o apoyando la economía doméstica. De esta manera, suponemos que aquellas unidades o módulos de riego con mayor edad promedio de los jefes de unidad de producción, serán las zonas donde la economía agrícola es más importante para el ingreso familiar.

En la bibliografía sobre sistemas productivos se considera importante la vinculación entre las características socioproductivas de las unidades de producción con los arreglos particulares de las unidades domésticas. Estas unidades determinan en gran medida la distribución del esfuerzo familiar en una actividad agropecuaria u otra alternativa, así como en algunos casos explica la persistencia de ciertos cultivos con respecto a otros.

El número de personas que aportan a la economía familiar es variable, pero resalta el hecho de que en la mayoría de los casos se concentra en una persona que aporta a la economía familiar. Llama la atención que en el caso de las unidades de riego, tiende a ser ligeramente mayor el número de personas que aportan en promedio, que con respecto a los distritos de riego. Esto se explica por el hecho de que la agricultura es una actividad económica ligeramente más importante entre los usuarios de la gran irrigación.

Los resultados de la encuesta muestran que si bien la agricultura es la principal fuente de ingresos de los usuarios de las unidades y módulos de riego, no son pocas las personas que declaran contar con una o dos fuentes adicionales de ingresos: $56.1 \%$ de los encuestados manifestó que tiene 


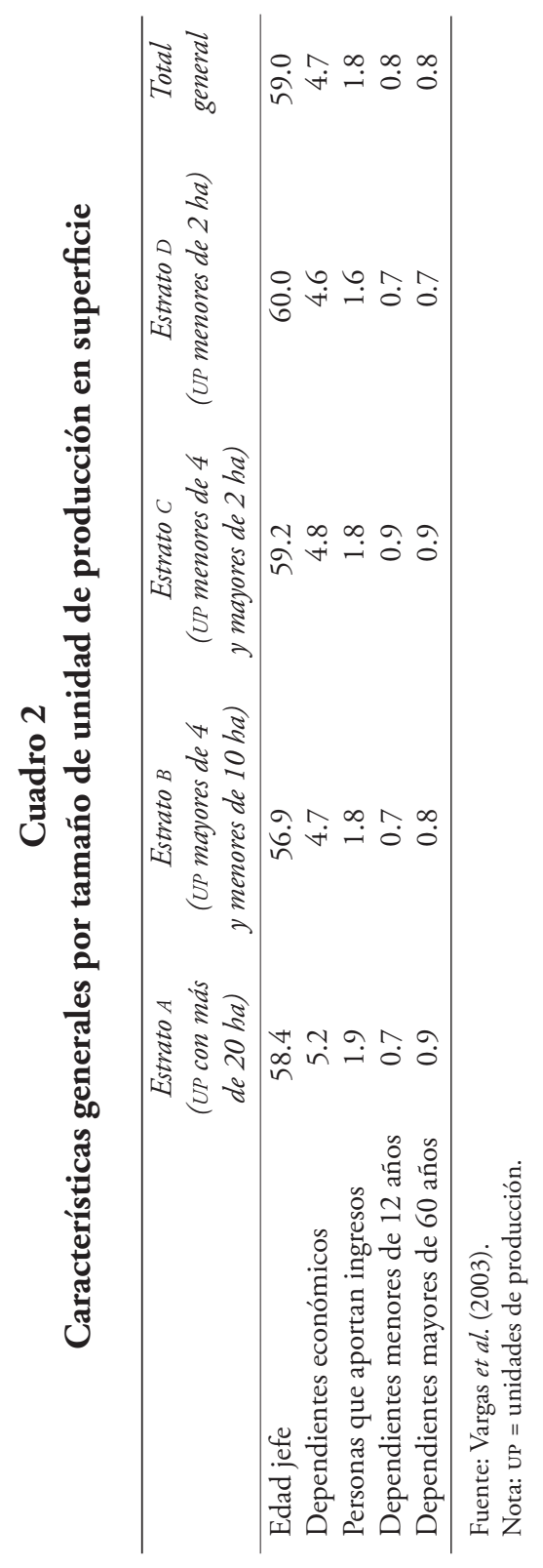


por lo menos otro ingreso. Las fuentes de ingresos adicionales más importantes fueron las siguientes: en primer lugar se encuentran las remesas de los migrantes a Estados Unidos (una cuarta parte de los encuestados dijo tener este tipo de ingresos); en segundo lugar están los recursos obtenidos por algún comercio o negocio (16.6\%); en tercero se ubican quienes tienen ingresos como jornaleros, ya sea temporales o permanentes (la suma de ambos es de 16.7\%); por último están los que tienen ingresos como empleados, $11.4 \%$ de los encuestados.

Si observamos estos datos al interior de las unidades y módulos estudiados, encontramos que en general se mantienen estas cuatro fuentes de ingreso como las más importantes. Las remesas que envían de Estados Unidos nuestros paisanos se constituye como la fuente alterna de ingresos más importante en prácticamente todos los distritos/unidades de riego (en la unidad El Gallinero más de la mitad, 55.6\%, dice contar con estos ingresos), las excepciones son los distritos de La Begońa y Rosario-Mezquite, donde los negocios y comercios ocupan el primer lugar. Los ingresos adicionales obtenidos como empleados son importantes en las unidades de riego Santa Ifigenia, El Tule y Garabatos. Los lugares donde ocupan un lugar importante los ingresos generados por los jornaleros agrícolas son las unidades Mariano Abasolo y Cofradía y los distritos de Zamora y Alto Río Lerma.

Analizando los ingresos de acuerdo con el tamaño de la unidad de producción, encontramos que hay una mayor diversificación de las fuentes de ingreso a medida que las unidades son más pequeńas. Para los grupos más pequeños, el D (de 0 a 2 ha) y el c (de 2 a 4 ha), la diversificación de las fuentes de ingreso es muy relevante: alrededor de $80 \%$ de estas unidades productivas tiene más de un ingreso económico. En cambio, $50 \%$ de las unidades productivas del grupo A (con más de $20 \mathrm{ha}$ ) tiene un ingreso adicional a la agricultura (cuadro 3).

El ingreso agropecuario representa más de la mitad del ingreso total para $76.5 \%$ de los encuestados y menos de la mitad para $22.6 \%$. No se advierten diferencias significativas según distrito/unidad de riego o por ubicación en la demarcación en su conjunto. En este sentido, para la mayoría de ellos la producción agrícola sigue siendo el eje de la economía agraria, aunque no se debe dejar de considerar la importancia de las remesas de los migrantes desde Estados Unidos y de los ingresos por negocio o comercio. Al mismo tiempo, destaca la poca importancia que tiene la venta de fuerza de trabajo (temporal o permanente), así como la renta de propiedades y el cobro de pensiones. 


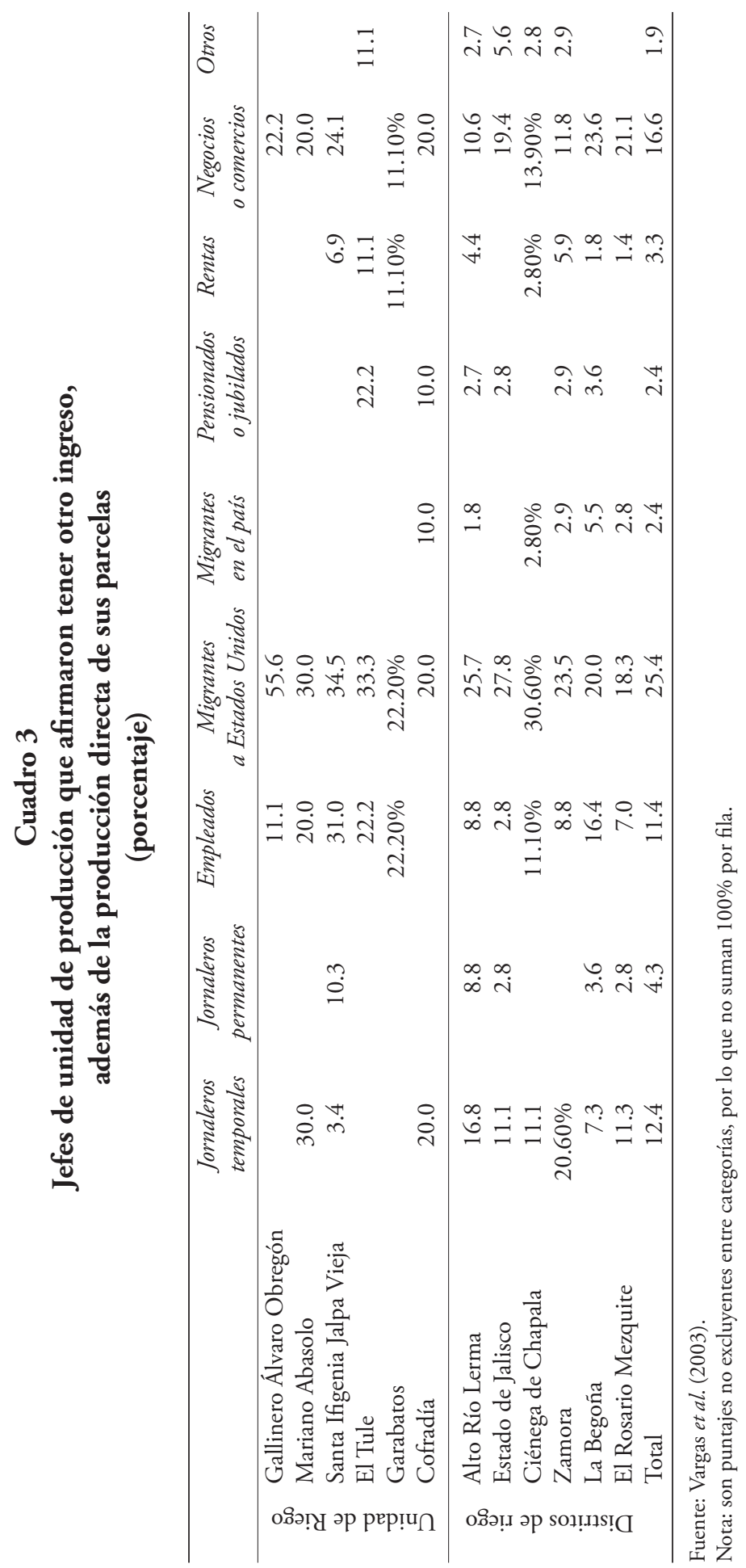




\subsection{Acceso a la tierra}

El tamaño total de las parcelas es variable. Si se comparan las parcelas promedio obtenidas mediante el padrón de usuarios en los casos en que se dispuso de ellos, se observa una tendencia a la concentración de superficies. Sin embargo, en la muestra, $13.2 \%$ cuenta con unidades de producción de dos hectáreas o menos. El tamaño promedio de las unidades de producción en la cuenca es de 9.5 hectáreas; el promedio más grande se encontró en las unidades La Cofradía (20.83 ha) y Santa Ifigenia (16.2 ha); por su parte, los distritos con mayores promedios en tamaño de parcela son Rosario Mezquite (11.03 ha) y Zamora (10.97 ha). Los lugares donde se encuentran las parcelas más pequeñas son las unidades $\mathrm{El}$ Gallinero y La Begoña, con poco menos de cinco ha. Los datos de la encuesta de 2003 indican que, en general, la mayoría de las unidades productivas de la cuenca cuentan con pocas hectáreas de labor; menos de la mitad de las unidades productivas (48\%) tienen menos de cinco ha en producción; por su parte, $28.6 \%$ de agricultores tienen unidades de hasta 10 ha; finalmente, el grupo de agricultores con más de 10 ha se compone apenas por $23.6 \%$ de los usuarios entrevistados.

Analizando la concentración de la tierra al interior de las unidades y distritos de la cuenca, encontramos que las unidades de riego donde están las parcelas más pequeñas son: El Gallinero (aquí no hay parcelas de más de 10 ha), Mariano Abasolo y Cofradía; en estas unidades la mitad de las parcelas tienen menos de cinco ha, aunque en la segunda está muy polarizado el tamaño de la parcela, pues $40 \%$ tiene parcelas de más de 10 ha. Al contrario, la unidad Santa Ifigenia o Jalpa Vieja tiene casi la mitad de sus parcelas con más de 10 ha. En los datos de los distritos de riego encontramos que los que tienen más problemas de minifundismo son La Begońa y Zamora, donde más de $60 \%$ de los usuarios tienen parcelas menores de cinco ha; este fenómeno se expresa también, aunque en menor medida, en los distritos 011 y 064, ahí más de la mitad de las parcelas están en ese rango. En cambio, el distrito donde se observa mayor concentración de tierras es Rosario Mezquite, ahí 41\% de los usuarios tiene parcelas mayores de 10 ha. El distrito que le sigue en tamaño de parcelas es el estado de Jalisco con 58.3 de las unidades productivas mayores de cinco ha. Un dato adicional es la difusión de la práctica del rentismo. Sin importar el tamaño de la unidad productiva, buena cantidad de los usuarios toman en renta tierras, no obstante hay que resaltar que en la medida en que crece el tamaño de la parcela es mayor la cantidad de tierra que se renta.

Para analizar un poco con más detalle estos procesos, podemos ver lo que ocurre en específico en el caso del distrito 011, el principal de la 


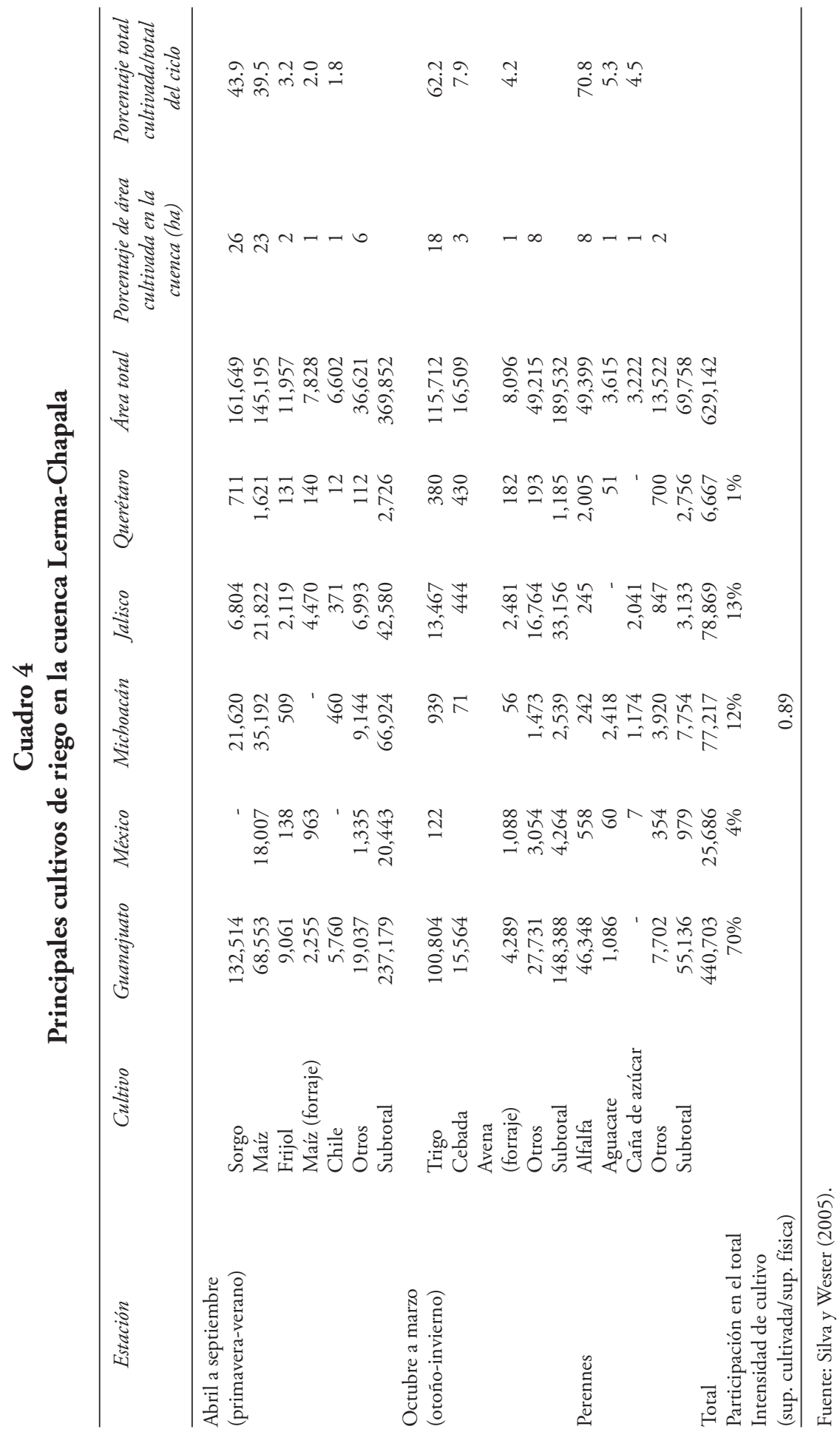


cuenca, donde existe un proceso de concentración de recursos productivos mediante la expulsión de productores no rentables, el desarrollo del rentismo y la agricultura por contrato y las agroindustrias. Si comparamos la encuesta aplicada en el Programa de Desarrollo Parcelario (Prodep) en 1991, y otra en 1999 para evaluar el proceso de transferencia por el IMTA, en el distrito de riego 011 (Vargas, 2000), podemos identificar una disminución en el número de unidades de producción con menos superficie entre 1991 y 1999 (50\%), pero en conjunto continúan sosteniendo su participación en superficie, lo que hace ver que aumenta su superficie por unidad de producción. En los sectores de más de cinco ha aumenta el número de unidades de producción sin que ascienda la superficie bajo control, lo que hace descender un poco la superficie por unidad de producción. Este proceso de concentración en muchos casos no implica expulsión total y permanente de productores campesinos de la agricultura, sino más bien la reorganización como unidades domésticas, donde la agricultura queda en un segundo o tercer lugar como generadora de ingresos. Esto se manifiesta en el caso del distrito 033, donde pese al efecto de los cambios económicos, la agricultura de subsistencia se sostiene con fuertes tasas de migración y pluriactividad de los miembros de las unidades domésticas de los jefes de unidad de producción (Vargas, 2007).

Estas diferencias se explican en parte por la distinta historia de acceso al agua de acuerdo con la relación de los sistemas de riego con el gobierno federal. En los distritos de riego se gestionó el agua de manera burocrática por parte de técnicos del gobierno federal, lo que llevó al establecimiento de un fuerte vínculo organizativo y político con las autoridades federales, las cuales invirtieron durante décadas la mayor parte del presupuesto en infraestructura de riego. Es ahí donde el precio del agua se subsidió más hasta principios de la década de 1980, ya que cuando la política agraria o alimentaria así lo requería, hacía funcionar la política gubernamental para orientar el patrón de cultivos y la productividad manipulando el abasto y precio del agua. Esto posibilitó un mejor acceso a programas federales de crédito, tecnología y comercialización. En cambio, las unidades de riego quedaron en un segundo plano de los intereses estatales en la ampliación del riego, a pesar de su importancia en superficie y número de usuarios. Estos sistemas siempre mantuvieron el control de sus propios sistemas, a pesar de esporádicas intervenciones gubernamentales en varios de ellos.

Con respecto a la tenencia de la tierra en la región analizada, es abrumadoramente ejidal, pues $77.2 \%$ de los encuestados tiene tierras ejidales, $16.9 \%$ tiene tierras en propiedad privada, $5.2 \%$ propiedad mixta, y el $0.7 \%$ restante es posesionario o no contestó la pregunta. El resultado no varía si se analiza la situación según ubicación en la cuenca, ya que en la 
parte media (Gallinero Álvaro Obregón, Abasolo, Alto Río Lerma y La Begońa) y en la baja (estado de Jalisco, Ciénaga de Chapala, Zamora y Rosario Mezquite), la propiedad ejidal es la principal y mayoritaria forma de tenencia de la tierra. Igualmente, el resultado es similar al evaluar la tenencia según distrito o unidad de riego (cuadro 5).

En la información disponible por sistema, se muestra que existe una fuerte relación entre el tamaño de las unidades de producción y una serie de características de acceso a recursos productivos, estrategias productivas y de vida, las cuales se observan en muy variadas combinaciones de acuerdo con cada estructura agraria local. Esto se refleja en la contratación de trabajadores y en el uso de trabajo familiar en la unidad de producción, entre otros.

El patrón de cultivos tiende a polarizarse entre quienes se insertan internacionalmente y aquéllos que se concentran en cultivos poco riesgosos y con insumos baratos, aunque ampliando su superficie en producción. En el ámbito nacional, para los productores con características campesinas, los frijoles y el maíz, junto con los forrajes, siguen siendo los principales cultivos en la mayoría de ellos, tanto grandes como pequeños, en casi todas las regiones. Se observa incluso un aumento de la superficie sembrada de maíz, esencialmente en los predios más grandes con riego, lo que en parte ocurre a expensas de cultivos de mayor valor -como el trigo y las oleaginosas-, y los minifundistas siguen dependiendo del maíz (Davis, 2000). Es innegable el aumento en el cultivo del maíz cuando se examina la superficie de labranza. La expansión se registra sobre todo en los predios más grandes, con riego, en el periodo otońo-invierno, precisamente son las condiciones necesarias para diversificarse con cultivos de mayor valor. El promedio de superficie con monocultivo de maíz por unidad familiar se duplicó con creces entre 1994 y 1997, con lo cual se mantuvo la tendencia iniciada en el periodo anterior. Por su parte, la superficie con forrajes también creció a casi el doble. Este incremento deriva en parte de un aumento de casi $50 \%$ en las tierras de riego cultivadas, con lo cual se invierte la tendencia registrada en 1990-1994 de disminución de la superficie de riego (Davis, 2000). La conclusión es que son los productores modernizados que cuentan con riego quienes impulsan la expansión del maíz (Davis, 2000).

Estos cambios se ven claramente en la los sistemas de riego de la cuenca, ya que existen dos estrategias muy concretas entre los agricultores medios y grandes. Entre los agricultores medios se muestra una tendencia hacia la extensificación, ya que son éstos quienes concentran la producción de granos. Una mayor superficie en producción sin incrementar la inversión de capital por hectárea, con relativos aumentos en la productividad, les ha permitido permanecer como agricultores. En cambio, los grandes 


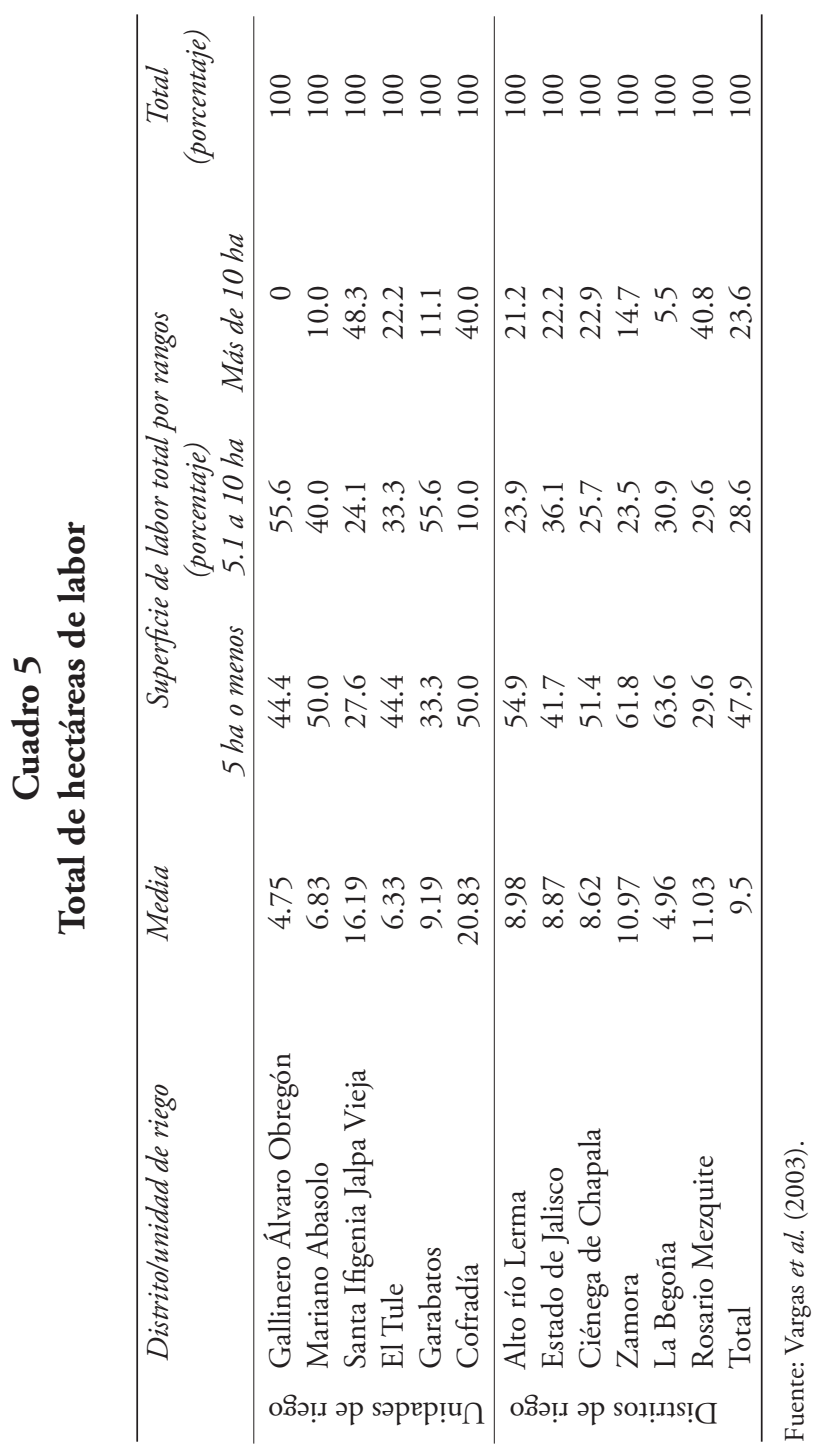


productores se han caracterizado por establecer un fuerte vínculo con el entramado de agroindustrias, intermediarios y exportadoras de productos agrícolas, en fresco y procesados. Este sector se ha venido fortaleciendo desde la segunda fase orientada hacia afuera del desarrollo agrícola en El Bajío, desde 1982 hasta ahora, el cual ha tendido a concentrase en zonas donde prevalece el uso de agua de los acuíferos, razón por la cual, al concentrase la encuesta de 2003 en zonas de riego de agua superficial, está poco representado en este informe, aunque se pueden mostrar datos de las características de estos productores que concentran superficies mayores de 200 o 500 hectáreas.

El Bajío como zona hidroagrícola comprende la parte media y sur de Guanajuato, después de las presas Tepuxtepec y Solís -las más grandes de la cuenca-, una parte del norte de Michoacán y los alrededores de la Ciénega de Chapala, incluyendo una pequeña porción de Jalisco. En el cuadro 6 se observa todavía la importancia de la cuenca en la producción de granos, como sorgo, maíz y trigo, los cuales representan el mayor porcentaje de superficie sembrada, donde Guanajuato es el que aporta mayor proporción: $70 \%$ de la superficie cultivada.

La superficie de hortalizas y cultivos más rentables e intensivos en agua no representan una gran superficie con respecto al total, pero en valor son muy significativas. En este estrato de productores se encuentran aquellos empresarios agrícolas que funcionan como principales brokers al mismo tiempo que productores de ciertos cultivos. Se menciona la existencia de un grupo de siete grandes productores agroindustriales en los que se concentra la mayor parte de la agroindustria y exportación en fresco (Wester, 2008), entre los cuales se encuentran las familias Usabiaga, Zaratini, Fox, entre otros, ubicados precisamente en la parte de la cuenca correspondiente a Guanajuato. Generalmente asociada a su propia producción, con alta tecnología de riego y producción, estos agricultores tienen su propia agroindustria y, ya sea que le venden a uno de los principales intermediarios, o ellos mismos comercializan a mercados lejanos, sobre todo en Estados Unidos.

Las agroindustrias localizadas en El Bajío ejercen control sobre la producción agrícola en diversos grados sobre la base de mecanismos de precios, paquetes tecnológicos, origen de agua utilizada y la selección de los agricultores que las abastecen. Las empresas procesadoras de hortalizas con frecuencia firman contratos con los productores, así obtienen el control sobre todo el proceso de producción. Estos contratos establecen con gran detalle el paquete tecnológico que se puede usar (semillas, fertilizantes, fechas de siembra y cosecha) y se fija un precio base, dependiendo de la calidad del producto. Por su parte, la empresa suministra a los productores crédito, asistencia técnica y maquinaria. Estos productores se con- 


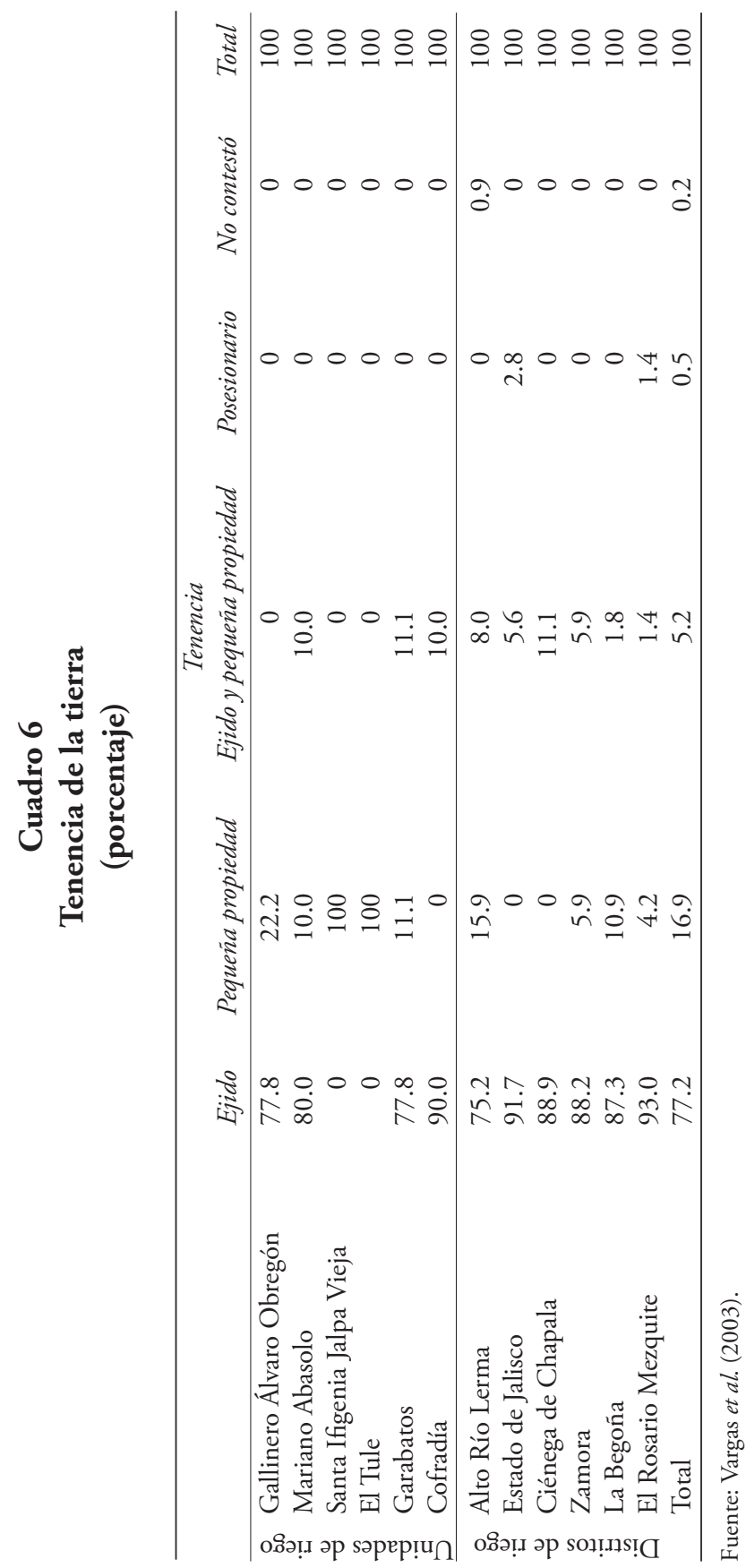


centran en el distrito de riego 011, Alto Río Lerma, y son prácticamente inexistente en la cuenca alta (arriba de las presas Solís y Tepuxtepec).

En cuanto al financiamiento, son muy pocos los productores que lo tienen formalmente. Éste lo tienen los productores globalizados y cierto segmento de productores de básicos. Otros acceden al crédito mediante arreglos contractuales con las empresas a las que venden su producción, sobre todo hortalizas. Otra tendencia es la ganaderización, ya que hay un sesgo para incorporar cultivos forrajeros e invertir en ganado como actividad alternativa. Sin embargo, la tecnificación es limitada, principalmente en la ganadería de traspatio.

\subsection{Acceso al agua}

Uno de los supuestos del enfoque modernizador es que, en un contexto económico desfavorable, es posible la modernización de un amplio sector de productores. Sin embargo, la información disponible sugiere que el uso de tecnología nueva disminuye en un amplio sector de productores, aunque sí existe un mejoramiento en la productividad por hectárea. Hay que resaltar que los incrementos en la productividad, esta última respuesta, no permite compensar la baja en su rentabilidad y por tanto en el ingreso de los productores. El sector que incorpora tecnología es el que se encuentra asociado a procesos de agroindustrialización, en un tipo de producción ajeno a la racionalidad campesina, de lo que en los países desarrollados ha dado en llamarse agricultura industrial. Sin embargo, prácticas como la siembra directa y el uso de tubería de baja presión o tubería de compuertas se han generalizado, ya que son de mínimo costo y permiten incrementar la eficiencia en el uso del agua en situación de mayor escasez.

Al cambiar el patrón de cultivos se transforma el patrón de uso del agua. Esto es muy claro en el distrito de riego 011, donde la escasez de este recurso está generando estrategias de eficiencia en su uso, aunque no la disminución en las extracciones, ya que las mejores tecnologías para hacer uso del agua llevan al productor a expandir su producción, y no a reducir su consumo. Este fenómeno ha hecho que se fortalezca el mercado del agua, sustancialmente entre usuarios con acceso a agua subterránea y usuarios de sólo agua superficial. Aquí impera la racionalidad económica, pues el agua se ve como un recurso productivo estratégico a corto plazo. La percepción respecto al servicio de riego está marcada por la ubicación socioeconómica de los productores y por su grado de participación en las decisiones respecto al servicio de riego. También existe una percepción diferente sobre el servicio de riego de acuerdo con el grado de consolidación de los módulos de riego. 


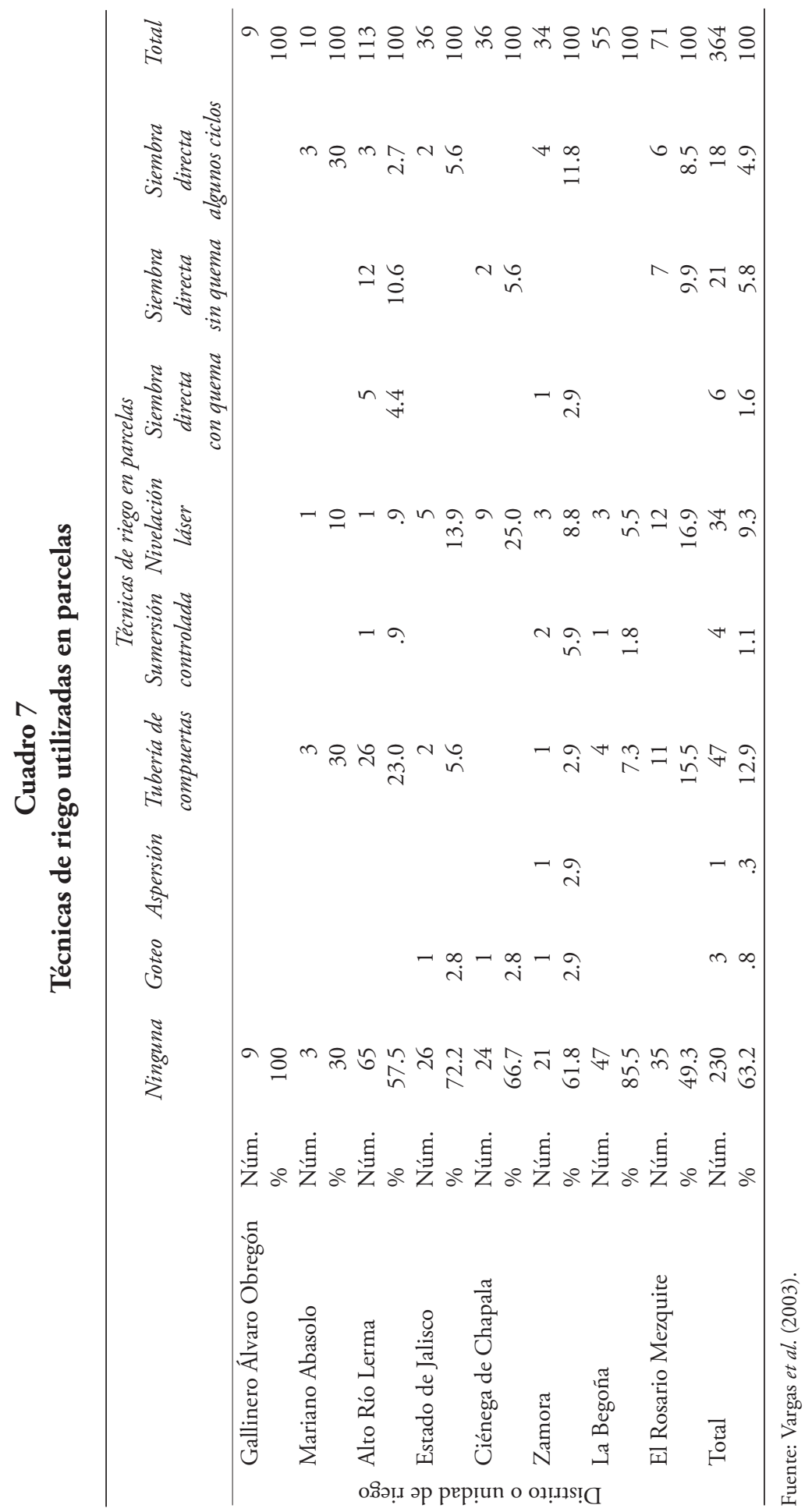


El acceso al agua es diferente entre los agricultores con riego de agua superficial. En general se muestra que la mayoría de los encuestados utilizan agua de canal, y el acceso a otras formas de riego es bastante diferenciado.

La encuesta arroja que básicamente existen siete formas de acceder al riego: canal, pozo, canal y pozo, bombeo directo de río, aguas negras, bombeo directo de dren y humedad. Como era de esperarse, dado el objetivo de la encuesta, el acceso al agua de riego por medio de canal, es la manera más recurrente, si no la única, que utilizan los usuarios de los distintos sistemas de riego. En el caso de las unidades de riego encontramos que en cuatro de las seis consideradas, el agua de canal es el único medio para acceder al riego, sólo en el caso de Mariano Abasolo una tercera parte bombea directamente del río y en Santa Ifigenia (o Jalpa Vieja), $14 \%$ tiene acceso a agua de pozo y $3.4 \%$ a ambas fuentes de abasto (figura I)

\section{Figura I}

\section{Tipo de riego por tamańo de unidad productiva}

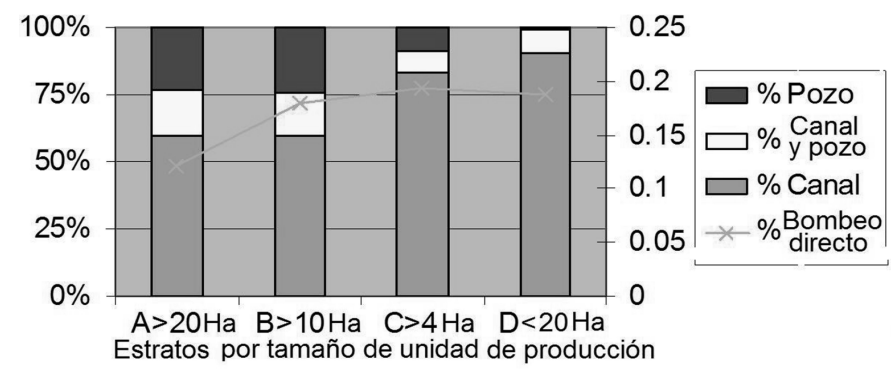

Fuente: Vargas et al. (2003).

En el caso de los distritos de riego, existe una mayor diversidad en cuanto a las fuentes de abastecimiento. En general también predomina el acceso al agua vía canal, en tres distritos $(011,033$ y 085) más de $80 \%$ de los usuarios dependen de esta fuente de abastecimiento; sin embargo, hay distritos donde el bombeo directo del río es muy importante, por ejemplo en el Rosario Mezquite más de la mitad (53.5\%) accede al agua por medio de bombeos directos del río Lerma, en la Ciénega de Chapala lo hace $33.3 \%$. El acceso al agua vía pozo es importante en distritos como en el estado de Jalisco, donde $27.8 \%$ tiene acceso a pozos, en RosarioMezquite así lo hace $21.1 \%$ y en Alto Río Lerma 18.6\%. En lo que respecta a lo usuarios que combinan el uso de agua de canal y de pozo, el 
DR Rosario-Mezquite es donde se da el mayor porcentaje con $28.2 \%$ de los usuarios.

Sólo un agricultor de toda la muestra reconoció que cultiva con base en aguas negras, en el distrito de riego de Zamora, en una superficie en el rango de cuatro a seis hectáreas, a pesar de que es una práctica bastante generalizada pero no reconocida oficialmente. De igual manera, el porcentaje de agricultores con superficies de riego de bombeo del dren fue de cinco, concentrados en parcelas de dos a cuatro hectáreas, en la Ciénega de Chapala tres, uno en Zamora y otro en Rosario Mezquite. La agricultura por humedad sólo se realiza por un agricultor en la Ciénega de Chapala, en una parcela menor a una hectárea.

En lo referente a la posibilidad de acceder a agua de pozo encontramos que 112 usuarios manifiestan que sus parcelas están en posibilidad de ser regadas por esta vía, lo cual representa $26.4 \%$ del total de la muestra. Aparentemente no hay una relación directa entre el tamaño de la parcela y la posibilidad de regar con pozo, como vemos, el mayor porcentaje se ubica entre las parcelas ubicadas en el rango de dos a cuatro ha con $30.4 \%$, aunque en segundo lugar se ubica la gente con 12 o más hectáreas, de estos, $20.5 \%$ dice poder regar con pozo.

El 29.9\% de las familias encuestadas afirma que cuenta en sus parcelas con tuberías de conducción. Este valor se distribuye de manera diferenciada por distritos/unidades de riego, lo que es revelador de la forma en que se reparte el apoyo gubernamental (federal y estatal) para la tecnificación del riego. Gallinero Álvaro Obregón (0\%), Ciénaga de Chapala (5\%), en un extremo, y Abasolo (50\%) y Rosario Mezquite (46.5\%), en el otro extremo, son una muestra de esta asimetría en el acceso a las tuberías de compuertas.

El riego punteado, que contribuye a un mejor desarrollo del cultivo, tiene mucha importancia, se trata de $75.5 \%$ de las familias encuestadas, y poca importancia para $7.1 \%$ de las mismas. El resto (17.3\%) no corresponde porque no utiliza este riego. La elevada cuantía del riego punteado se extiende a todos los distritos/unidades de riego, con excepción de Gallinero Álvaro Obregón (33.3\%) y a toda la cuenca (media y baja).

Del universo de entrevistados, más de la mitad (56\%) no ocupa regadores. El 30.2\% piensa que los regadores no desperdician más agua que un agricultor y $10.7 \%$ opina lo contrario, en la región de la cuenca. Los que dicen que sí se ubican mayormente en el estado de Jalisco (22.2\%), Ciénaga de Chapala (19.4\%), Rosario Mezquite (16.9\%) y La Begoña (14.5\%).

La mayoría de los productores entrevistados (56\%) nunca contrata regadores. Un 25\% lo hace de manera habitual y el 19\% restante los requiere ocasionalmente. Esto revela que en la cuenca el propio productor, 
apoyado por sus familiares, es el que se encarga del riego. Por distritos/ unidades de riego la mayoría de los que nunca contratan regadores se encuentran en Gallinero Álvaro Obregón (77.8\%) Alto Río Lerma (65.5\%), La Begoña (61.8\%) y Mariano Abasolo (60\%). Por tanto, son estas mismas agrupaciones las que menos contratan habitual u ocasionalmente regadores, y todas ellas están ubicadas en la cuenca media.

El 60\% de los productores no utiliza ninguna de las nuevas técnicas de riego, más allá del surcado que requiere su cultivo en particular. El 12.9\% utiliza tubería de compuerta, 9\%, nivelación láser. El 5.8\% siembra directa sin quema y $4.9 \%$ la siembra directa por ciclos. Esta imagen global evidencia que pese al discurso y al esfuerzo gubernamental realizado desde mediados de los noventa, poco se ha logrado para introducir en los campos de cultivo técnicas que contribuyan al ahorro de agua en el riego. Nuevamente la distribución de quienes no utilizan ninguna técnica es bastante diferenciada: $100 \%$ en Gallinero Álvaro Obregón, 85.5\% en La Begoña y $72.2 \%$ en el estado de Jalisco. En la gráfica I observamos cómo los grandes y medianos productores tienen mayor acceso al agua de pozo. En el caso del bombeo directo del río, quienes más acceden a esta fuente de abasto son los medianos, pequeños y muy pequeños productores.

\section{Gráfica I \\ Innovación por tamańo de unidad productiva}

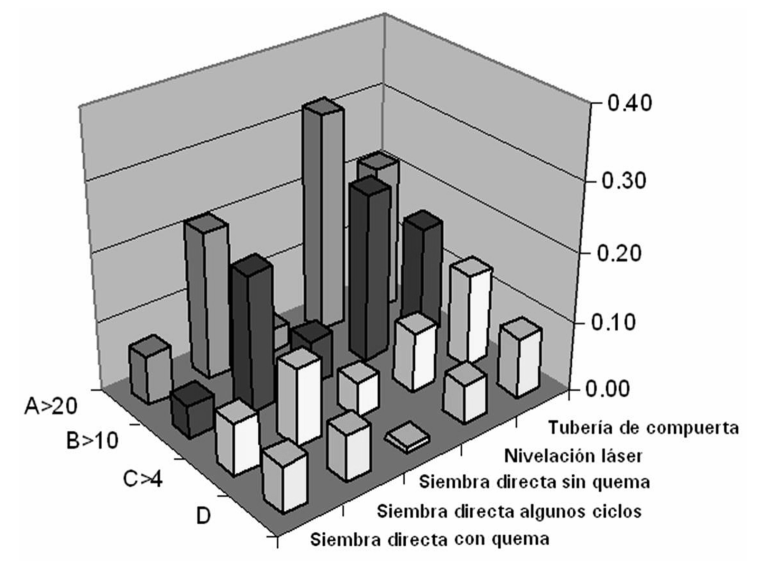

Fuente: Vargas et al. (2003).

La regularidad con que se utilizan tuberías de compuerta es baja: 5.5\% afirma que mucho, otra proporción igual respondió que poco, y $1.9 \%$ que no la utiliza. El 86.8\% no corresponde. Por tanto, el acceso las tecnologías no sólo es reducido, asimétrico, sino también hay una escasa 
regularidad en su utilización. Más de dos terceras partes de los entrevistados sostiene que el servicio de entrega de agua de canal es muy bueno o bueno (68.4\%), 29.7\% que es malo o pésimo y $1.9 \%$ no opinó o no contestó. Por tanto, es indudable que la mayoría de los productores tiene una buena opinión de la calidad del servicio de riego.

\section{La negociación por el agua entre los agricultores}

En general existen niveles de información bajos, considerando que el proceso de movilización por el agua, así como la discusión pública respecto a los trasvases al lago de Chapala deberían involucrar más a los agricultores de toda la región. En general se manifestó un conocimiento muy bajo entre los agricultores de pequeña irrigación, lo cual expresa la poca vinculación que tienen con el arreglo institucional y la problemática del lago de Chapala y el manejo de las grandes presas. Como se muestra más adelante, sólo $15.10 \%$ afirmó conocer lo que es el Consejo de Cuenca Lerma-Chapala. En el caso de las unidades de riego, se explica el bajo conocimiento por el tipo de vinculación que tienen con el arreglo institucional del agua, es decir, a estos agricultores les resulta muy difuso identificar qué instituciones locales, estatales o federales tienen que ver con el agua, y con qué funciones. Lo que resulta contradictorio es que en el distrito de riego 011, el cual ha mostrado mayor movilización por el agua y contra los trasvases, existe un bajo nivel de conocimiento del espacio institucional en el cual se resuelve su problemática del agua.

El 59.9\% de los entrevistados afirmó conocer lo que son los trasvases, mientras que $39.8 \%$ dijo lo contrario. Por distritos-unidades de riego las percepciones son diferenciadas, pues mientras que en el Alto Río Lerma se encuentra la proporción más baja (48.7\%), lo contrario ocurre en Ciénaga de Chapala (80.6\%). Uno de los mayores problemas con las políticas hidráulicas es el desconocimiento por parte de los actores, principalmente los sociales, del arreglo institucional básico para la gestión del agua. Sólo $15.1 \%$ de los entrevistados afirmó conocer qué es el Consejo de Cuenca, pieza central de la nueva orientación de la política hidráulica en el país. Nuevamente, por distritos-unidades de riego las respuestas son diferenciadas, pues mientras que en La Begońa sólo 10.9\% sostiene que conoce este elemento del nuevo arreglo institucional, en el estado de Jalisco y Ciénaga Chapala 25\%, en ambos casos, tiene una respuesta positiva.

Acerca de las expectativas de los agricultores, prevalece un pesimismo respecto a la actuación de las entidades gubernamentales, ya que existe un sentimiento de abandono de la política pública respecto de su situación, así como una deslegitimación. Sólo 19.8\% de los entrevistados afirma que se tienen en cuenta, en buena medida, los intereses de los agriculto- 
res con riego en la región, $46.4 \%$ muy poco, $32.1 \%$ sostiene que nada, y $1.7 \%$ no sabe o no responde. La mayor aceptación se encuentra en Abasolo (40\%) y la menor en La Begoña (7.3\%).

\section{Reflexiones finales}

Los agricultores de la cuenca Lerma-Chapala muestran una amplia estratificación en términos de sus estrategias productivas y de uso del agua. Se puede afirmar que en cuanto a su organización social por el agua, cada sistema presenta sus propias características hidrológicas y sociales que llevan a la necesidad de establecer procesos de gestión específicos para cada caso. En la cuenca alta, correspondiente principalmente al Estado de México, la agricultura de subsistencia es dominante. Si bien esta región aporta el mayor volumen de agua a las grandes presas de El Bajío -la cuenca media-, el uso del agua para riego y su productividad son bajos. En la cuenca media, ubicada sobre todo en Guanajuato, debajo de la presa Solís, se concentra una agricultura comercial, en la que un estrato de grandes agricultores realiza una agricultura intensiva, incluyendo cultivos de exportación. Estos son quienes han capturado los espacios de representación de los agricultores en los consejos, comisiones y comités de cuenca y acuífero, lo cual se refleja en la poca información y percepciones de los agricultores de base en los distintos sistemas, aunque de manera diferenciada según sus características socioeconómicas y su ubicación.

Existe una problemática muy diferenciada entre cada sistema de riego, pues se muestra un patrón complejo de relaciones entre el tamaño de las unidades de producción, las características de los responsables de la producción, las formas de acceso al agua y su ubicación a lo largo de la cuenca. A pesar de la poca o mala información sobre la problemática de la cuenca y del arreglo institucional responsable de su manejo, entre los agricultores existen valores medioambientales positivos, que se expresan en una disposición a apoyar la recuperación del lago de Chapala y del río Lerma, siempre y cuando se realice en condiciones de equidad y compensación, y con base en una negociación que les parezca equitativa. Prevalece un bajo acceso a tecnologías de riego, a pesar de los distintos esfuerzos por transformarlas, pero debe reconocerse que la racionalidad económica -esfuerzo, costos y beneficios- de los agricultores los lleva a utilizar el agua de cierta manera, y que cualquier ahorro en sus sistemas se reutiliza para reforzar o ampliar su producción. El derroche de agua de riego por parte de los agricultores es un comportamiento económico racional en el actual marco institucional. El ahorro de agua que resulta de la implementación de las innovaciones técnicas no es un resultado 
buscado, sino una consecuencia involuntaria del cálculo económico general por parte de ellos (Mollard y Vargas, 2002c).

La problemática de tipo organizativa y propia del arreglo institucional de las asociaciones de usuarios de riego, dificulta a sus miembros establecer sanciones y estímulos apropiados con base en criterios compatibles con la conservación del recurso en toda la cuenca. En algunos casos contrasta lo que opina la base social de los agricultores con respecto a la problemática expresada por los miembros de la mesa directiva entrevistados. Existe una relación no simple entre la disposición a negociar y la disposición a movilizarse por el agua. Se manifiesta una brecha entre líderes y agricultores, en la que no son los mejor informados quienes están más dispuestos a movilizarse.

De este trabajo se desprende que es fundamental generar un proceso de comunicación sobre la situación de la cuenca. Es necesario construir una instancia que se considere neutral, capaz de desarrollar una interlocución no sólo en el ámbito institucional, sino con todos los actores sociales. Existe una importante disposición a apoyar la conservación del lago de Chapala y el cauce del río Lerma por parte de los agricultores, pero es importante generar una estrategia para captar este interés y dirigirlo mediante políticas apropiadas, con base en criterios de equidad.

\section{Bibliografía}

Bravo, Héctor (2007), Regular para preservar: el lago de Chapala como banco de agua, Centro de Investigación para el Desarrollo, México.

Caire, Georgina (2005), "Conflicto por el agua en la cuenca LermaChapala, 1996-2002”, Región y Sociedad, XVII (34), El Colegio de Sonora, México, pp. 73-125.

Comisión Nacional del Agua-Montgomery Watson (1999), Proyecto lineamientos estratégicos para el desarrollo hidráulico de la región Lerma-Santiago-Pacífico, diagnóstico regional, Conagua, Guadalajara. Versión en $\mathrm{CD}$.

Cosgrove, William J. y Frank R. Rijsberman (2000), Visión mundial del agua: que el agua sea asunto de todos, Earthscan Publications Ltd, Londres, www.worldwatercouncil.org/index.php?id $=9638 \mathrm{~L}=$ $0 \% 20$. 
Crinquant, Nicolas (2004), "Étude d'associations d'irrigants mexicains. Cas des Grandes Unités d'Irrigation de l'Etat de Guanajuato, Bassin versant Lerma Chapala”, tesis l'Ensam, París.

Iv Foro Mundial del Agua (2006a), Implementing Integrated Water Resources Management, Thematic Document, Framework Theme 2, México.

IV Foro Mundial del Agua (2006b), Desarrollo institucional y procesos políticos, Documento Temático Perspectiva Transversal B, México.

Davis, Benjamin (2000), "Las políticas de ajuste de los ejidatarios frente a la reforma neoliberal en México", Revista de la CEPAL, 72, www. eclac.cl/publicaciones.

Güitrón, Alberto (2005), "Modelación matemática en la construcción de consensos para la gestión integrada del agua en la cuenca Lerma Chapala”, en S. Vargas y E. Mollard (eds.), Los retos del agua en la cuenca Lerma-Chapala. Aportes para su estudio y discusión, IRDIMTA, Morelos, México.

Keller, Jack, Andrew Keller y Grant Davids (1998), "River Basin Development Phases and Implications of Closure", Journal of Applied Irrigation Science, 33 (2), Kassel, Alemania, pp. 145-163.

Michelson, William y Willem Van Vliet (2002), "Theory and the sociological study of the built environment", en R. Dunlap y W. Michelson (eds.), Handbook of environmental sociology, Greenwood Press, Londres, pp. 70-95.

Mollard, Eric y Sergio Vargas (2002a), "Actores, iniciativas y conflictos en situación de transición política e institucional. Un primer acercamiento a la cuenca Lerma-Chapala”, Segundo Encuentro Chapala, El Colegio de Michoacán-Universidad de Guadalajara, Chapala, Jalisco.

Mollard, Eric y Sergio Vargas (2002b), “QQue se seque el pinche lago! Las asociaciones de usuarios de riego ante los retos ambientales", vI Congreso de la Asociación Latinoamericana de Sociología Rural (Alasru), Porto Alegre, 25-29 de noviembre. 
Mollard, Eric y Sergio Vargas (2002c), "La racionalidad del 'derroche' del agua a nivel de los regantes", Memorias del Xvir Congreso Nacional de Hidráulica, Asociación Mexicana de Hidráulica, Monterrey, México.

Mollard, Eric y Sergio Vargas (2004), "Liable but not guilty: The political use of circumstances in a river basin council (Mexico)", en Proceedings of the Workshop on Water and Politics: Understanding the Role of Politics in Water Management, World Water CouncilIUCN, Marsella, 26-27 de febrero.

Mollinga, Peter P. (2008), "Water, politics and development: Framing a political sociology of water resources management", Water Alternatives, 1 (1), http://www.water-alternatives.org/index.php? option=com_frontpage\&Itemid=1, pp. 7-23.

O’Donnell, Guillermo y Philippe Schmitter (1998), Transiciones desde un gobierno autoritario, vol. 4, Conclusiones tentativas sobre las democracias inciertas, Paidós, Buenos Aires.

Silva, Paula y Ph. Wester (2005), "Water demand and use at basin level", en E. Mollard, S. Vargas y P. Wester, Comprehensive Assessment of Water Management in Agriculture. Comparative study on river basin development and management, The Lerma-Chapala Basin, Mexico, Universidad de Wageningen-IRD-IMTA, Project Report to International Water Management Institute, Wageningen, Países Bajos, p. 302.

Vargas, Sergio (2000), "Las tendencias socioeconómicas en el DR 011 1", I Congreso Internacional de Transferencia de Sistemas de Riego, Mazatlán, Sinaloa, 2-9 de abril, memorias en CD.

Vargas, Sergio (2007), "Agua y sociedad en los sistemas de riego de la cuenca del Alto Lerma”, Agricultura, Sociedad y Desarrollo, 4 (1), Colegio de Posgraduados, México, pp. 1-17.

Vargas, Sergio (2008), "El conflicto y la negociación en la percepción de los usuarios del agua en la cuenca Lerma-Chapala, 1999-2004", Revista Legislativa de Estudios Sociales y Opinión Pública, 1 (1), Cesop, México, pp. 155-183. 
Vargas, Sergio y Eric Mollard (2005a), "Contradicción entre las expectativas ambientales de los agricultores y la defensa de sus intereses en la cuenca Lerma-Chapala", en Sergio Vargas y Eric Mollard (eds.), Problemas socioambientales y experiencias organizativas en las cuencas de México, IMTA-IRD, México, pp. 64-82.

Vargas, Sergio y Eric Mollard (eds.) (2005b), Los retos del agua en la cuenca Lerma-Chapala: aportes para su estudio y discusión, IMTAIRD, México.

Vargas, Sergio, Eric Mollard, Roberto Romero y Daniel Murillo (2003), "Evaluación social de los escenarios de manejo de agua superficial en la cuenca Lerma-Chapala”, informe final del proyecto CP0322, y anexos, IMTA-CNA, México.

Vargas, Sergio, Boris Marañón, Roberto Romero, Eduardo López, Denise Soares, Lázaro Cano y Jaime Suaste (2005), “Diagnóstico para la implementación de proyectos que permitan la conservación del acuífero de Pedro Escobedo-San Juan Del Río, Querétaro", informe final del proyecto CP-0517.3, IMTA, Morelos, México.

Wester, Phillippus (2008), Shedding the waters. Institutional Change and Water Control in the Lerma-Chapala Basin, Mexico, Wageningen Universiteit, Países Bajos.

Wester, Phillippus, Sergio Vargas, Eric Mollard y Paula Silva (2008), "Negotiating Surface Water Allocations to Achieve a Soft Landing in the Closed Lerma-Chapala Basin, Morelos, Mexico", International Journal of Water Resources Development, 24 (2), pp. 275-288.

Recibido: 6 de junio de 2008. Reenviado: 26 de agosto de 2008. Aceptado: 3 de septiembre de 2009.

Sergio Vargas-Velázquez. Es doctor en antropología por la Universidad Iberoamericana, realizó estudios de sociología en FLACSO y de economía en la Universidad Autónoma Metropolitana-Azcapotzalco. Es miembro del Sistema Nacional de Investigadores, nivel I. Desde 1990 labora en el Instituto Mexicano de Tecnología del Agua (IMTA), donde ha investigado sobre la problemática social en torno al agua: organización de los agricultores de riego, el proceso de transferencia de los distritos de riego a asocia- 
ciones de usuarios, la formación de consejos, comisiones y comités de cuenca y acuífero y otros aspectos de la implementación de la gestión integrada de los recursos hídricos (GIRH), como conflictos y gobernanza del agua. Entre sus publicaciones recientes se encuentran: en coautoría, "El agua para riego como bien económico y social", Revista de Estudios Agrarios, 39, México, pp. 23-47 (2008); "Negotiating Surface Water Allocations to Achieve a Soft Landing in the Closed Lerma-Chapala Basin, Mexico", International Journal of Water Resources Development, 24 (2), Routledge, Atizapán, México, pp. 275-288 (2008), http://www.tandf.co.uk/journals/journal.asp?issn=0790-0627\&linktype $=44$. 